\title{
IN VITRO AND IN SILICO LIPOXYGENASE INHIBITION STUDIES AND ANTIMICROBIAL ACTIVITY OF PYRAZOLYL-PHTHALAZINE-DIONES
}

\author{
Vesna M. Milovanović ${ }^{1}$, Zorica D. Petrović ${ }^{1}$, Vladimir P. Petrović1, \\ Dušica Simijonovićc ${ }^{* 1,4}$, Milan Mladenović ${ }^{2}$ Nevena Tomašević 2 , \\ Ljiljana R. Čomić ${ }^{3}$, Ivana D. Radojević3
}

${ }^{1}$ University of Kragujevac, Faculty of Science, Department of Chemistry, Radoja Domanovića 12, 34000 Kragujevac, Serbia

${ }^{2}$ Kragujevac Center for Computational Biochemistry, Department of Chemistry, Faculty of Science, University of Kragujevac, Radoja Domanovića 12, 34000 Kragujevac, Serbia

${ }^{3}$ University of Kragujevac, Faculty of Science, Department of Biology and Ecology, Radoja Domanovića 12, 34000 Kragujevac, Serbia

${ }^{4}$ University of Kragujevac, Institute for Information Technologies, Kragujevac, Jovana Cvijića bb, 34000 Kragujevac, Serbia

* Corresponding author; E-mail: dusica.simijonovic@pmf.kg.ac.rs

(Received March 5, 2021; Accepted April 7, 2021)

\begin{abstract}
The series of pyrazolyl-phthalazine-dione derivatives (PPDs) was subjected to evaluation of their in vitro lipoxygenase (LOX) inhibition and antimicrobial activities. Results obtained for LOX inhibition activities of PPDs showed that all compounds exhibit good to excellent activity, whereby compounds with eudesmic, syringic, vanillic or toluic moiety are the most active. Molecular modelling study was performed to investigate the possible mechanism of action and binding mode of compounds within the LOX active site. Docking results revealed that activity of the examined compounds depends on the functional group ability to create hydrogen bond accepting (HBA) and hydrophobic features (Hy) in the LOX-Ib active site. In addition, all substances were tested for their antibacterial and antifungal activities. The investigated compounds showed better antifungal than antibacterial activity. The highest antifungal activity was on Aspergillus fumigatus ATTC 204305 and Trichoderma viridae ATCC 13233.
\end{abstract}

Keywords: pyrazolyl-phthalazine-dione derivatives, anti-inflammatory activity, molecular docking, antimicrobial activity.

\section{INTRODUCTION}

Heterocycles with pyrazole and phthalazine moiety have been the topic of research because of their large number of biological properties. These compounds exert activities such as, antibacterial (LV et al., 2010), anticonvulsant (GRASSO et al., 2000), antiviral (GENIN et 
al., 2000), cardiotonic (NOMOTO et al., 1990), antitumor (WeI et al., 2006), antiinflammatory (NAKAMURA et al., 2003), vasorelaxant (WATANABE et al., 1998), antifungal (RYU et al., 2007), cytotoxic (KIM et al., 2008), anticancer (EL-SAKKA et al., 2009) and anticoagulant (XIA et al., 2007). The pyrazolo and phthalazine derivatives have found applications in biologically active pharmaceuticals, functional materials as well as in agrochemicals (BERGSTROM, 1944; LiCHTENTHALER, 2002; NABID et al., 2010). In addition, tacrine-like pyrazolo[1,2-b]phthalazine compounds are reported as selective and potent inhibitors of acetylcholinesterase (AChE), and could be effective drugs for Alzheimer therapy (JALILI-BALEH et al., 2017). It is important to emphasize that there are commercially available drugs which contain phthalazine or pyrazole moiety, such as Vatalanib (PTK-787) (ASIF, 2015), Zopolrestat (MYLARI et al., 1991), Hydralazine (Groves et al., 1985), Imonabant (CURIONI and ANDRÉ, 2006), CDPPB (UsLANER et al., 2009), Betazole (SEGAL et al., 1959) (Fig. 1).

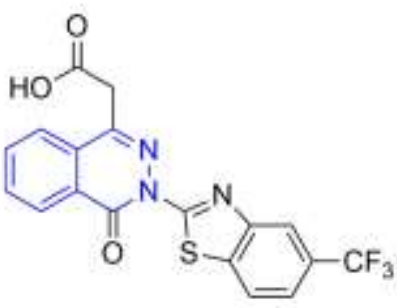

Zopolrestat Antidiabetic

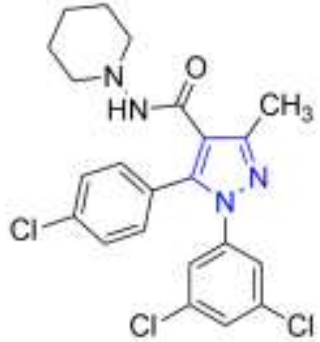

Rimonabant

Anti-obesity

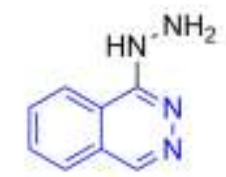

Hydralazine

Antihypertensive

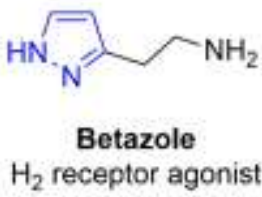

$\mathrm{H}_{2}$ receptor agonist

Anti-psychotic

Figure 1. Commercially available drugs with phthalazine or pyrazolo moiety.

Lipoxygenases (LOXs) present a group of oxidative enzymes which can be found in plants and mammalian. The mammalian LOX catalyzes the oxygenation of arachidonic acid, while linoleic acid is the primary substrate of the plant LOX (VINAYAGAM et al., 2017; WISASTRA and DEKKER, 2014). The active site in soybean LOX is non-heme Fe(III)-ion coordinated by three histidines, asparagine, isoleucine, and a hydroxy group. The LOX active site with part of linoleic acid, as substrate, is presented in Fig. 2 (PHATAK et al., 2012).

Soybean LOX is a homologue of mammalian LOX and most of studies have used soybean LOX to find efficient LOX inhibitors. Very often LOX inhibitors are antioxidants or free radical scavengers (Petrović et al., 2009; PONTIKI and HAdJIPAVlou-Litina, 2018). LOXs are responsible for the synthesis of leukotrienes, potent inflammatory mediators, that cause various pathological processes such as bronchial asthma, epithelial cancers-prostate, human colon cancer and allergic rhinitis (PETROVIĆ et al., 2018). For these reasons, finding efficient LOX inhibitors present challenge for many scientists. In literature, several types of 
inhibitors have been reported, such as: redox inhibitors, non-redox inhibitors, FLAP inhibitors, iron-chelator inhibitors, and leukotriene antagonist (SIMIJONOviĆ et al., 2018; WiSASTRA and DEKKER, 2014). Literature is scarce with data that relate to in vitro LOX inhibitory activity and docking study of pyrazoles and phthalazines derivatives, and there are a few such papers ( ABDELALL et al., 2016; ABD El RAZIK et al., 2017; Hu and MA, 2018).

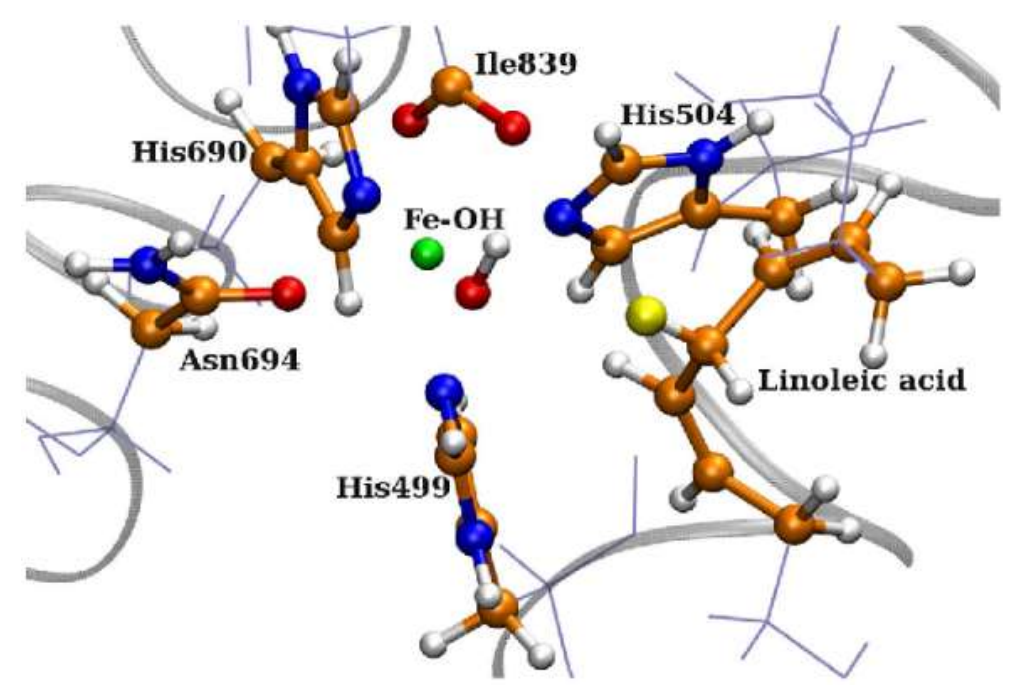

Figure 2. The active site in soybean LOX.

Recently, synthesis of pyrazolyl-phthalazine-dione derivatives (PPDs) was reported (Fig. 3), (SimiJONOVIĆ et al., 2018) as well as their antioxidative effects.

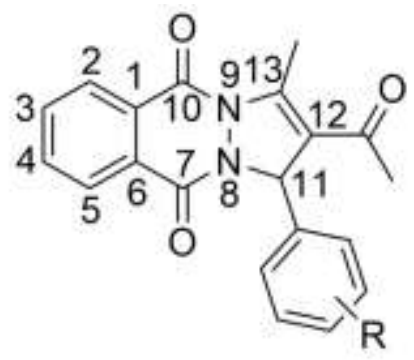

$$
\begin{aligned}
& \text { PPD-1 R }=\mathrm{H} \\
& \text { PPD-2 R }=4-\mathrm{CH}_{3} \\
& \text { PPD-3 R }=4-\mathrm{Cl} \\
& \text { PPD-4 R }=4-\mathrm{F} \\
& \text { PPD-5 R }=4-\mathrm{NO}_{2}
\end{aligned}
$$

$$
\begin{aligned}
& \text { PPD-6 R }=4-\mathrm{OH} \\
& \text { PPD-7 R }=3,4-\text { diOH } \\
& \text { PPD-8 } \mathrm{R}=4-\mathrm{OH}-3-\mathrm{OCH}_{3} \\
& \text { PPD-9 R }=4-\mathrm{OH}-3,5-\text { diOCH }_{3} \\
& \text { PPD-10 R }=3,4,5-\text { triOCH }_{3}
\end{aligned}
$$

Figure 3. General structural formula of the investigated compounds PPD-1-10 with atom labeling used in Structure-based activity relationships section.

Excellent antioxidant activities of compounds with catechol and syringic moiety (2acetyl-1-(3,4-dihydroxyphenyl)-3-methyl-1H-pyrazolo[1,2-b]phthalazine-5,10-dione (PPD7) and 2-acetyl-1-(4-hydroxy-3,5-dimethoxyphenyl)-3-methyl-1H-pyrazolo[1,2-b] phthalazine-5,10-dione (PPD-9) exerted $\mathrm{IC}_{50}$ values of 4.1 and $14.6 \mu \mathrm{M}$ against 1,1-diphenyl-2picryl-hydrazyl (DPPH) radical motivated us to examine anti-inflammatory activities of these compounds. Namely, it is known that antioxidants may behave as effective LOX inhibitors (Petrović et al., 2009; Pontiki and HadjiPAVlou-Litina, 2018). On the other hand, literature data regarding the antimicrobial activity of compounds with pyrazo-phthalazine 
moiety documents that these substances exhibit good antibacterial and antifungal activities. According to this, these compounds target microbial growth and could be a good starting material to find new more active compounds (SHAH et al., 2012; SANGANI et al., 2016). Therefore, the aim of this study was to continue with investigation of the biological activities of recently synthetized PPDs.

\section{MATERIALS AND METHODS}

\section{General procedure for the synthesis of pyrazolyl-phthalazine-dione}

The procedure for synthesis of the pyrazolyl-phthalazine-dione (PPD-1-10), as well as their corresponding spectral characterization are given in reference (SIMIJONOVIĆ et al., 2018).

\section{Biological experiments}

\section{In vitro study of soybean lipoxygenase inhibition}

The determination of the soybean lipoxygenase inhibition of the PPDs was performed according to the previously described methodology. (PONTIKI and HADJIPAVLOU-LITINA, 2007) The tested PPDs were dissolved in DMSO and incubated at room temperature with sodium linoleate $(100 \mu \mathrm{l})$ and $200 \mu \mathrm{l}$ of enzyme LOX type Ib solution $\left(1 / 9 \times 10^{-4} \mathrm{w} / \mathrm{v}\right.$ in saline $)$ and buffer tris $\mathrm{pH}$ 9. The conversion of sodium linoleate to 13-hydroperoxylinoleic acid at $234 \mathrm{~nm}$ was recorded and compared with the NDGA as standard inhibitor. The results presented as mean values \pm standard deviation (SD) of three independent measurements. The standard deviation was calculated in Office 365 Excel program 2104 by using equation:

$$
S T=\sqrt{\frac{\sum_{i=1}^{N}\left(x_{i}-\bar{x}\right)^{2}}{N-1}}
$$

\section{In vitro antimicrobial assays}

\section{Test microorganisms}

Antimicrobial activity of methanol and ethyl acetate extract was tested against eight strains of bacteria and 10 strains of fungi. The list of tested microorganisms is presented in Tabs. 2 and 3. All clinical isolates were a generous gift from the Institute of Public Health, Kragujevac. The other microorganisms were provided from a collection held by the Microbiology Laboratory, Faculty of Science, University of Kragujevac.

\section{Suspension preparation}

The suspensions were prepared by the direct colony method (ANDREWS, 2005). The turbidity of the initial suspension was adjusted using 0.5 McFarland standard whit densitometer (DEN-1, BioSan, Latvia). The initial bacterial and yeast suspensions were additionnally diluted in 1:100 ratio in sterile $0.85 \%$ saline. The resulting bacterial suspension contains about $10^{6}$ colony forming unites $(\mathrm{CFU}) / \mathrm{mL}$ and suspension of yeast contains $10^{4} \mathrm{CFU} / \mathrm{mL}$. The suspensions of fungal spores were prepared from 3- to 7-day-old cultures that grew on a potato dextrose agar. The spores were prepared by gentle stripping of spores from slopes with growing mycelia with sterile $0.85 \%$ saline, used to determine turbidity spectrophotometrically at $530 \mathrm{~nm}$ according to NCCLS (NCCLS, Wayne, PA, USA). The resulting suspensions were approximately $10^{4} \mathrm{CFU} / \mathrm{mL}$. 


\section{Microdilution method}

The antimicrobial activity was tested by determining the minimum inhibitory concentration (MIC) and the minimum microbicidal concentration (MMC) using the microdilution method with resazurin (SARKER et al., 2007). The stock concentration of tested substances was $2000 \mu \mathrm{g} / \mathrm{mL}$. The tested compounds were dissolved in DMSO and then diluted into a nutrient liquid medium to achieve a concentration of $10 \%$. Twofold serial dilutions of tested substances were made in sterile 96-well plates containing Mueller-Hinton broth (Torlak, Beograd) for bacteria and Sabouraud dextrose broth (Torlak, Belgrade) for fungi. The tested concentration range was from $1000 \mu \mathrm{g} / \mathrm{mL}$ to $7.81 \mu \mathrm{g} / \mathrm{mL}$. After that, the plates were inoculated with the suspensions to give a final concentration of $5 \times 10^{5} \mathrm{CFU} / \mathrm{mL}$ for bacteria and $5 \times 10^{3} \mathrm{CFU} / \mathrm{mL}$ for fungi. The growth of bacteria and yeasts was monitored by adding resazurin $(67.5 \mathrm{mg} / 10 \mathrm{~mL})$. Resazurin is a blue non-fluorescent dye that becomes pink and fluorescent when reduced to resorufin by oxidoreductases within viable cells. The inoculated plates were incubated at $37^{\circ} \mathrm{C}$ for $24 \mathrm{~h}$ for bacteria, $28{ }^{\circ} \mathrm{C}$ for $48 \mathrm{~h}$ for yeasts and $28{ }^{\circ} \mathrm{C}$ for $72 \mathrm{~h}$ for molds.

MIC was defined as the lowest concentration of tested substances that prevented resazurin color change from blue to pink. For molds, MIC values of the tested substances were determined as the lowest concentration that visibly inhibited mycelia growth. MMC was determined by plating $10 \mathrm{~mL}$ of samples from wells, where no indicator color change was recorded, on nutrient agar medium. At the end of the incubation period the lowest concentration with no growth (no colony) was defined as MMC.

Doxycycline and fluconazole, dissolved in nutrient liquid medium, were used as positive controls, $10 \%$ DMSO was used as a negative control. It was observed that $10 \%$ DMSO did not inhibit the growth of microorganisms. Each test included growth control and sterility control. All tests were performed in duplicate, and MICs were constant.

\section{Molecular modeling experiments}

\section{The structure crystal preparation soybean lipoxygenase}

To the best of our knowledge, there are no crystal structures containing cocrystallized structures of compounds investigated in this study with soybean lipoxygenase. Therefore, molecular docking was performed on soybean lipoxygenase-Ib (PDB ID: 5T5V) (SRIVASTAVA et al., 2016; TORRES et al., 2013). Initially, the protein was prepared for molecular modelling after being loaded into the UCSF Chimera v1.10.1 software (PETTERSEN et al., 2004) for Linux 64 bit architecture and visually inspected. Protein was then energy minimized as follows: through the leap module of the Amber suite (CASE et al., 2012) they were solvated with water molecules (TIP3 model, SOLVATEOCT Leap command) in a box extending $10 \AA$ in all directions, neutralized with either $\mathrm{Na}^{+}$or $\mathrm{Cl}^{-}$ions, and refined by a single point minimization using the Sander module with maximum 1000 steps of the steepest-descent energy minimization followed by maximum 4000 steps of conjugategradient energy minimization, with a non-bonded cut off of $5 \AA$.

\section{Generation of 1 H-pyrazolo[1,2-b]phthalazine-5,10-dione derivatives}

All of the $1 H$-pyrazolo[1,2- $b$ ]phthalazine-5,10-dione derivatives were modelled by applying the Chemaxon's msketch module, (BEANS, 2015) by means of molecular mechanics' optimization upon which the hydrogen atoms appropriate to $\mathrm{pH} 7.4$, were assigned,

\section{Molecular docking protocol}

The active site definition was performed upon the $\mathbf{5 T 5 V}$ crystal had been aligned to soybean lipoxygenase-3 co-crystallized with 13(s)-hydroperoxy-9(Z),11(E)-octadecadienoic acid (PDB ID: 1IK3) (SKRZYPCZAK-JANKUN et al., 2001), by means of UCSF Chimera 
MatchMaker module. The protein part of 1IK3 crystal was prepared similarly to the 5T5V one. Thus, an 1IK3 inhibitor was extracted from the complex after which either protein or ligand were improved by assigning the hydrogen atoms at $\mathrm{pH}$ of 7.4 and Amber parameters (CASE et al., 2012) using Antechamber semi-empirical QM method. Upon the thorough examination, the A chain of each complex was retained for further manipulation and aligned to obtain common relative coordinates. The prepared structures of 5T5V and 1IK3 were imported into AutoDockTools graphical user interface. Nonpolar hydrogen atoms were removed while Gasteiger charges and solvent parameters were added. All of the tested compounds were used as ligands for docking. The rigid root and rotatable bonds were defined using AutoDockTools. The docking on 5T5V was performed with AutoDock 4.2 (MORRIS et al., 2009) by applying the cuboid docking grid coordinates provided from 1IK3 complex as follows: the xyz coordinates (in Angströms) for the computation were $\mathrm{Xmin} / \mathrm{Xmax}=8.328 / 31.096, \mathrm{Ymin} / \mathrm{Ymax}=-15.291 / 15.029, \mathrm{Zmin} / \mathrm{Zmax}=3.579 / 31.555$; the coordinates setup was performed in a manner to embrace the minimized inhibitor spanning $10 \AA$ in all three dimensions. The Lamarckian Genetic Algorithm was used to generate orientations or conformations of ligands within the binding site. The procedure of the global optimization started with a sample of 200 randomly positioned individuals, a maximum of $1.0 \times 10^{6}$ energy evaluations and a maximum of 27000 generations. A total of 100 runs were performed with RMS Cluster Tolerance of $0.5 \AA$.

\section{RESULTS AND DISCUSSION}

\section{In vitro lipoxygenase inhibition}

The UV absorbance-based soybean lipoxygenase assay is often used as an analysis model for indication of compounds anti-inflammatory activity (MÜLLER, 1994). Therefore, the soybean LOX was selected for evaluation of anti-inflammatory potential of PPDs. Obtained results revealed that all examined compounds exhibit $\mathrm{IC}_{50}$ anti-LOX activity in range of 24-49 $\mu \mathrm{M}$, Tab. 1. Namely, the compounds PPD-2 and PPD-10 provided the highest LOX inhibition ( $\mathrm{IC}_{50}=24.42$ and $\mathrm{IC}_{50}=24.10 \mu \mathrm{M}$ ), followed by PPD-8 and PPD-9 with activities of $\mathrm{IC}_{50}=28.36$ and $\mathrm{IC}_{50}=27.84 \mu \mathrm{M}$. Compounds PPD-1, PPD-4, and PPD-5 exhibit activities in the range of 33-38 $\mu \mathrm{M}$, while compounds PPD-3, PPD-6, and PPD-7 exert low activities.

Table 1. Compounds PPD-1-10 estimated and energies of binding ( $\left.\Delta \mathrm{G}_{\text {bind }}\right)$ predicted inhibition constants $\left(\mathrm{K}_{\mathrm{i}}\right)$.

\begin{tabular}{cccc}
\hline Compounds & $\mathbf{I C}_{\mathbf{5 0}}(\boldsymbol{\mu M})$ & $\boldsymbol{A G}_{\text {bind }}(\mathbf{k c a l} / \mathbf{m o l})$ & $\boldsymbol{K}_{\mathbf{i}}(\boldsymbol{\mu} \mathbf{M})$ \\
\hline PPD-1 & $38.01 \pm 0.15$ & -5.6 & 106.64 \\
PPD-2 & $24.42 \pm 0.94$ & -5.3 & 127.49 \\
PPD-3 & $33.97 \pm 0.11$ & -5.6 & 101.34 \\
PPD-4 & $33.10 \pm 0.35$ & -5.7 & 100.79 \\
PPD-5 & $36.29 \pm 0.72$ & -5.7 & 102.78 \\
PPD-6 & $49.01 \pm 0.63$ & -5.0 & 139.54 \\
PPD-7 & $41.97 \pm 0.14$ & -5.0 & 134.24 \\
PPD-8 & $28.36 \pm 0.09$ & -5.6 & 117.64 \\
PPD-9 & $27.84 \pm 0.15$ & -5.8 & 102.41 \\
PPD-10 & $24.10 \pm 0.48$ & -6.1 & 99.53 \\
\hline
\end{tabular}

Results of $\mathrm{I} \mathrm{C}_{50}$ values represent mean values \pm standard deviation (SD) of three independent measurements. 


\section{Structure-based activity relationships}

As the tested compounds have been experimentally confirmed as LOX-Ib inhibitors, their activity profile was further on fulfilled on the structure-based level. Compounds calculated free energies of binding $\left(\Delta \mathrm{G}_{\text {bind }}\right)$ and predicted inhibition constants $\left(K_{\mathrm{i}}\right)$ are reported in Tab. 1. Thus, in the best-docked conformation of PPD-10, as the most active LOX-Ib inhibitor (Tab. 1), the 1,2,3,4-tetrahydro-phthalazine core of $1 H$-pyrazolo[1,2- $b]$ phthalazine5,10-dione basic scaffold is oriented towards the T-shaped hydrophobic clashes with Phe553 and Ile747, respectively, while the 2,3-dihydro-1 $H$-pyrazole ring is located in a hydrophobic pocket made of Ile548, Ile549, and Val746 (Fig. 4A). The precise orientation of the basic scaffold is also conditioned with the additional stabilization within the active site by means of C7 carbonyl oxygen (Figs. 3 and 4) involvement in strong hydrogen bonding with Gln491 $\left(d_{\mathrm{HB}}=1.886 \AA\right)$ and Gln693 $\left(d_{\mathrm{HB}}=2.859 \AA\right)$, respectively. Although located at the outer rim of the active site, the $\mathrm{C} 10$ carbonyl group also contributes to the overall PPD-10 alignment, by virtue of weak hydrogen bonding with the side-chain hydroxy group of Thr552 $\left(d_{\mathrm{HB}}=\right.$ 3.368 Å). Moreover, the C12's acetyl moiety and a C13 methyl group are trapped in a hydrophobic cage made of Thr255, Leu542, Ile548, and Val746. The bioactive conformation of PPD-10 is greatly influenced by the presence of the $m, m, p$-trimethoxyphenyl moiety, glued to the main core at $\mathrm{C} 11$. Thus, within the $\mathrm{C} 11$ substituent, the methyl group of the $p$ methoxy moiety is immersed in the hydrophobic pocket complied of Ala538, Trp496, Ile534, and Ile543. Moreover, $p$-methoxy's oxygen in narrow to a weak hydrogen bond with the His500's imidazole ( $d_{\mathrm{HB}}=3.336 \AA$ ) and faces the Fe(III) ion. In such manner, the discussed functional group bearing both, hydrogen bond accepting (HBA) and hydrophobic features (Hy), emphasize that the HBA-Hy features combination forms the LOX-Ib active site interior. On the other hand, the first $m$-methoxy group of PPD-10 represents the second HBA-Hy features, since it targets the hydrophobic interference with Ile492, Ile549, and Trp496 while its oxygen atom is HB-attracted by Gln491 side-chain amide group carbonyl $\left(d_{\mathrm{HB}}=3.066 \AA\right)$. Finally, the second $m$-methoxy group of PPD-10 is oriented toward the hydrophobic pocket compiled of Leu542, Ile534, and the side chain methyl group of Thr255. However, the nature of interactions with Thr255 is just an electrostatic, so the second $m$ methoxy group cannot be considered as the third HBA-Hy feature. Distinct alignment of PPD-10 is characterized with relatively low estimated value of free energy of binding $\left(\Delta \mathrm{G}_{\text {bind }}\right)$ of $-6.1 \mathrm{kcal} / \mathrm{mol}$ and the predicted inhibition constant $\left(K_{\mathrm{i}}\right)$ equal to $99.53 \mu \mathrm{M}$, which may be considered in agreement with the exerted potency.

Despite the significant differences in bio-poses between the LOX-Ib inhibitors, compound PPD-2 (Fig. 4B) surprisingly exhibits the activity comparable to the most active compound, PPD-10 (Tab. 1). However, the $\Delta \mathrm{G}_{\text {bind }}$ and $K_{\mathrm{i}}$ of PPD-2 are 1.15-fold lower and 0.78-fold higher than PPD-10, the values that cannot be associated with the high value of potency of compound. Still, distinct disparity between the $\mathrm{IC}_{50}$ and either $\Delta \mathrm{G}_{\text {bind }}$ or $K_{\mathrm{i}}$ was not a surprise and revealed the inevitable limitation of the scoring function, proving that no docking program can predict at the same the binding mode and $\Delta \mathrm{G}_{\text {bind }}$ or $K_{\mathrm{i}}$ (RAGNO et al., 2005, MLADENOViĆ et al. 2017). At the same time, this does not imply the inaccuracy of the obtained bioactive conformations, insofar as for all the reported conformations the best docked, and best clustered conformation (data not shown) were identical and were biochemically meaningful by means of the established interactions. Thus, the $1 \mathrm{H}$ pyrazolo[1,2- $b]$ phthalazine-5,10-dione scaffold of PPD-2 is subjected to the major movement out from the conformity provided by Phe553 and Ile747, after which two main cores are orthogonally aligned to each other. Thus, the main core's benzyl moiety is now encircled with Phe553, Val746 and Ile747, in a pyramidal structure. In comparison with compound PPD-10, the PPD-2's C7 carbonyl oxygen is not stabilized as before; it is directed toward the hydrophobic cage made of Thr255, Leu542, Ile548, and Val746. Instead, the C10 
carbonyl oxygen is narrow to a medium intensity hydrogen bond with the side chain $\mathrm{NH}_{2}$ group of Gln491 ( $d_{\mathrm{HB}}=3.090 \AA$ ). The latter amino acid side chain carbonyl group establishes additional electrostatic interactions with the main core's N9. Moreover, as a result of significant conformational change, the carbonyl group within the C12's acetyl moiety, as an HBA feature, forms a weak hydrogen bond with His500 $\left(d_{\mathrm{HB}}=3.099 \AA\right)$, an amino acid coordinatively bounded to Fe ion. The origin of the high activity of PPD-2 maybe strictly found in the particular hydrogen bond formation, inasmuch as the $\mathrm{C} 11 p$-methyl scaffold is protruding the area normally occupied by the first $m$-methoxy group (i.e. the first HBA-Hy feature) of PPD-10.
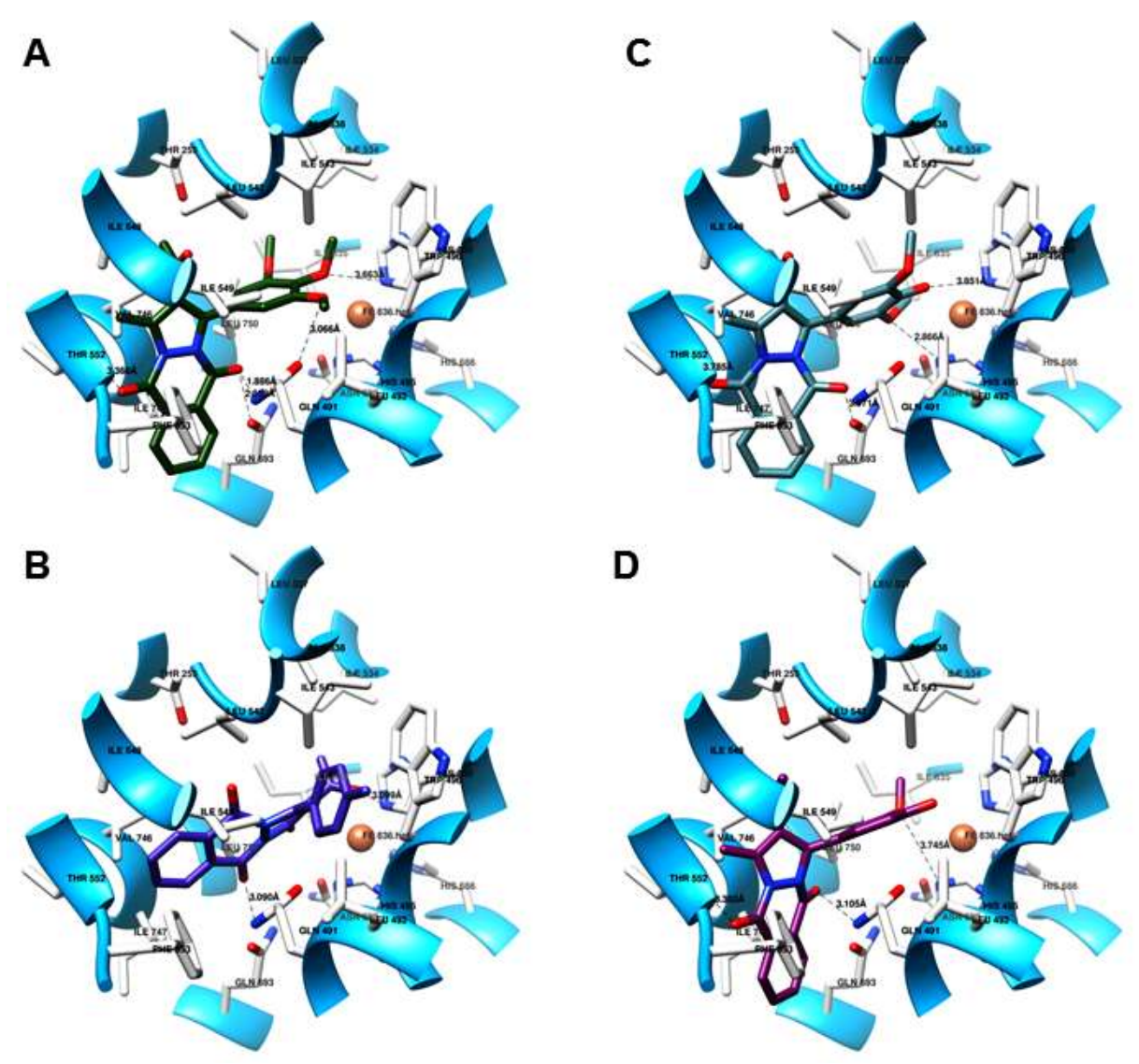

Figure 4. The bioactive conformation of PPD-10 (A); PPD-2 (B); PPD-9 (C); PPD-8 (D). The LOX-Ib amino acids are presented in white, the LOX-Ib ribbon is colored in blue. For the clarity purpose, only polar hydrogen atoms are presented.

The decreased activity of compound PPD-9 (Fig. 4C), in relation to the most active PPD-10, appears to be a consequence of the replacement of PPD-10's $p$ - $\mathrm{OCH}_{3}$ with $p$-OH group, likewise resulting in the increase of $\Delta \mathrm{G}_{\text {bind }}(-5.8 \mathrm{kcal} / \mathrm{mol})$ and lowering the $K_{\mathrm{i}}(102.41$ $\mu \mathrm{M})$. Here, $\Delta \mathrm{G}_{\mathrm{bind}}$ and $K_{\mathrm{i}}$ agreed with the experimentally determined potency. Otherwise, PPD-9 adopts comparable bioactive conformation to the one of PPD-10. Thus, the $p$ - $\mathrm{OCH}_{3}$ replacement with the $p-\mathrm{OH}$ group, as a hydrogen bond donor (HBD), has a great impact on the alignment of the PPD-9 C11-aromatic substituent since it is positioned $45^{\circ}$ in comparison to PPD-10's one. Consequently, the newly established $p-\mathrm{OH}$ group is narrow to a very weak HB with His500 $\left(d_{\mathrm{HB}}=3.851 \AA\right)$, reminding that the HBD to HBA-Hy changeover is mandatory, while the connection of the second HBA-Hy feature with Gln491 is lost. On the other hand, the second $m$-methoxy group this time becomes an HBA-Hy feature since it establishes strong hydrogen-bonding with His495 $\left(d_{\mathrm{HB}}=2.886 \AA\right)$, providing a basis for a reputable activity of PPD-9 (Tab. 1). 
Furthermore, the comparable activities of compounds PPD-9 and PPD-8 (Fig. 4D) are understandable since PPD-8 adopts bioactive conformation similar to the previously depicted compounds. The only structural change in the structure of PPD-8 related to PPD-9 is the absence of the $m-\mathrm{OCH}_{3}$ portion that would be in PPD-10 considered as a second HBAHy feature. Therefore, all the advantageous interactions with Ile492-Trp496-Ile549 and Gln491 are absent. The distinct lack of methoxy group most certainly affects the activity: there are no HBs between the $p-\mathrm{OH}$ and His495 and His500, respectively, and only mediumstrength hydrogen-bonding between $\left(d_{\mathrm{HB}}=2.886 \AA\right)$ the His 495 and the existing $m$-methoxy group (i.e. an HBA-Hy feature) provides the PPD-8 notable activity (Tab. 1). Likewise, distinct structural alternation increased significantly the $\Delta \mathrm{G}_{\text {bind }}(-5.1 \mathrm{kcal} / \mathrm{mol})$ and lowered the $K_{\mathrm{i}}(117.65 \mu \mathrm{M})$, confirming the suboptimal performance of the scoring function.
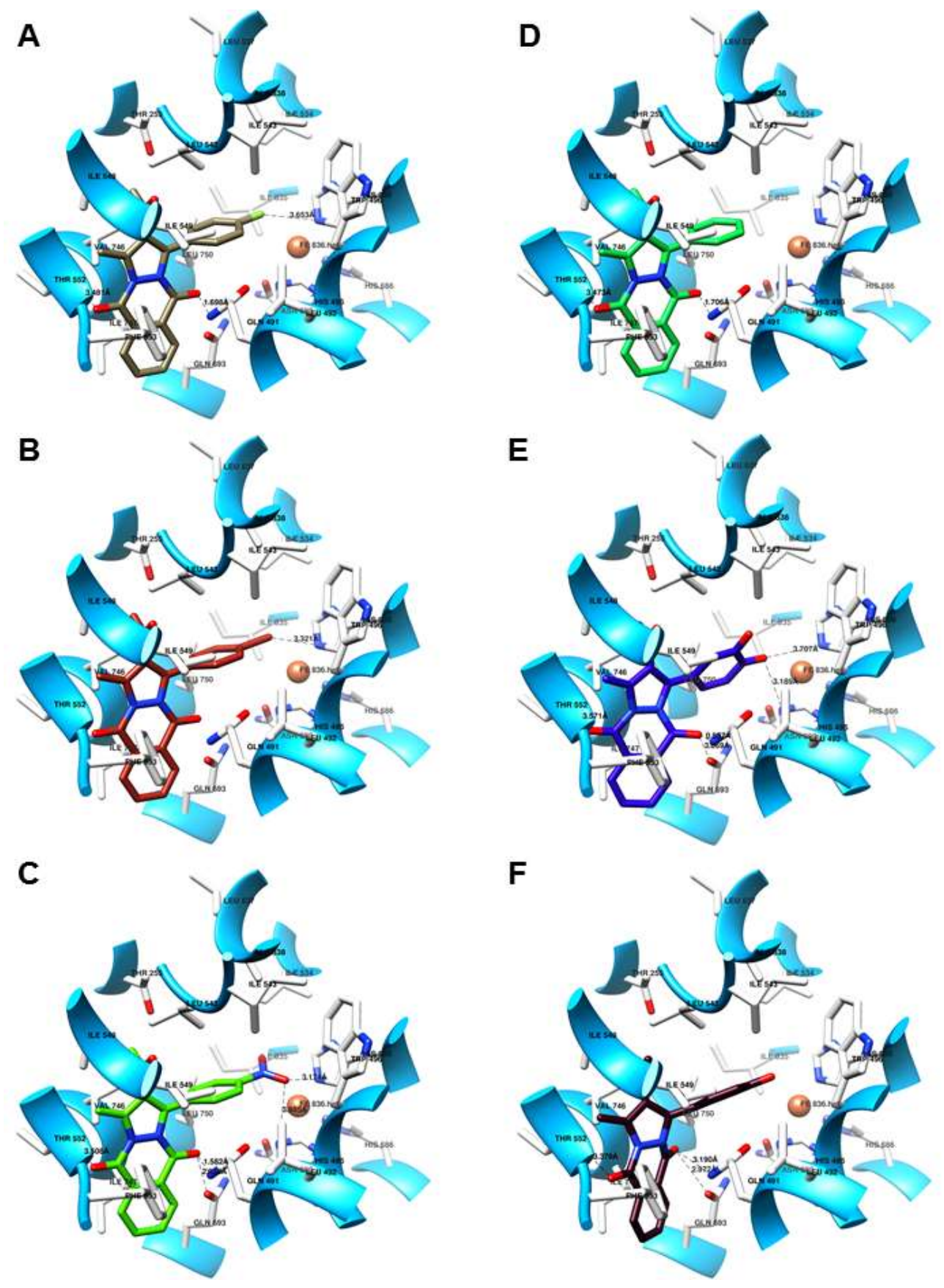

Figure 5. The bioactive conformation of PPD-4 (A); PPD-3 (B); PPD-5 (C); PPD-1 (D); PPD-7 (E); PPD-6 (F). The LOX-Ib amino acids are presented in white, the LOX-Ib ribbon is colored in blue. For the clarity purpose, only polar hydrogen atoms are presented. 
The triad of compounds containing $p-\mathrm{F}, p-\mathrm{Cl}$, and $p-\mathrm{NO}_{2}$ substituents (PPD-4, PPD3, and PPD-5, Tab. 1, Figs. 5A, 5B, and 5C, respectively) at position C11, were challenging to explain from the activity point of view. Adopting the same biorientation as the PPD-10, the discussed compounds prove that the functionalities bearing both hydrogen bond accepting (HBA) and hydrophobic features (Hy) (like methoxy ones, see the discussion for PPD-10) are more preferred in the active site that the ones characterized only by HBA characteristics ( $p-\mathrm{F}, p-\mathrm{Cl}$, and $p-\mathrm{NO}_{2}$ ). Hence, the HBA-related groups like $p-\mathrm{F}, p-\mathrm{Cl}$, and $p-\mathrm{NO}_{2}$ (as in PPD-4, PPD-3, and PPD-5, respectively) are simply not enough to provide higher activity, despite establishing weak HBs with His500 $\left(d_{\mathrm{HB}}=3.653,3.321\right.$, and $3.174 \AA$ A, Figs. 5A, 5B, and 5C, individually), weak electrostatic interactions/HBs with His495 (only PPD-5 establishes the particular $\mathrm{HB}, d_{\mathrm{HB}}=3.885 \AA$ ) (Figs. 5A, 5B, and 5C, separately), or only electrostatic interactions with Fe(III) ion Figs. 5A, 5B, and 5C, correspondingly). Paradoxically, PPD5 (Fig. 5C) is the only compound within the triad capable of making the HBs with both $\mathrm{Fe}(\mathrm{III})$-related His residues, by means of $p-\mathrm{NO}_{2}$ as a double HBA feature, but, at the same time, is of the worst activity, once again emphasizing the importance of HBA-Hy feature instead of HBA alone. While the obtained bioactive conformations somehow succeeded to differentiate the distinct triad by means of potency, the obtained $\Delta \mathrm{G}_{\text {bind }}$ values were identical for the triad of compounds. Still, there was a correlation between the drop in potency and drop in binding affinity (viz. $K_{\mathrm{i}}$ values).

However, if the C11-occupying benzene is not substituted at all (as in PPD-1), the best-docked conformation is still comparable with the bioactive conformation of the compound PPD-10, although with the significantly decreased activity (Tab. 1, Fig. 5D). The reason of the alleviated activity is the very absence of the $m, m, p$-trimethoxyphenyl moiety, after which all of the favorable interactions with the LOX-Ib Fe(III) -delimited active site seen in the bioactive conformation of PPD-10 are irrevocable lost. Interestingly, the scoring function was sensitive to distinct structure-activity alteration, as both $\Delta \mathrm{G}_{\text {bind }}$ and $K_{\mathrm{i}}$ were higher and lower than the ones of PPD-4, PPD-3, and PPD-5. Nevertheless, despite significant difference in the potency between the PPD-1 and PPD-2 their $\Delta \mathrm{G}_{\text {bind }}$ values were identical, emphasizing the $\Delta \mathrm{G}_{\text {bind }}$ as not a good parameter for estimating the potency of the herein compounds.

The importance of the $m-, m-, p$-trimethoxyphenyl moiety is more deeply understood after its structural modification within the least active compounds PPD-7 and PPD-6 (Tab. 1, Figs. 5E and 5F, respectively). Thus, the total elimination of the $p$-methoxy moiety equivalent to the PPD-10's second HBA-Hy feature, as well as the oxidation of the remaining $m$ and $p$-methoxy groups towards the $m$ - and $p$-OHs influenced the $45^{\circ}$ rotation of the PPD-7's C11-aromatic scaffold in comparison with the PPD-10, where only $p-\mathrm{OH}$ behaves as a HBD to either His495 $\left(d_{\mathrm{HB}}=3.189 \AA\right)$ or His500 $\left(d_{\mathrm{HB}}=3.707 \AA\right)$, while the $m$-OH moiety is lost in an active site hydrophobic pocket. Still, besides the advantageous interactions with the active site amino acids, the absence of the Hy contribution of PPD-7 inside the active site (i.e. the HBD feature conversion to HBA-Hy) makes the compound virtually inactive in comparison with PPD-10. On the other hand, the corresponding $p-\mathrm{OH}$ portion of PPD-6 is oriented towards the induced dipole interaction with Trp495. Consequently, PPD-6 is labelled as the leas active. Compounds' low potencies were associated with the highest $\Delta \mathrm{G}_{\text {bind }}$ values and the lowest $K_{\mathrm{i}}$ values, which were whatsoever, despite showing some correlation with the observed $\mathrm{IC}_{50} \mathrm{~s}$, poor indicators of the potencies. 
Table 2. Antibacterial activity of tested compounds.

\begin{tabular}{|c|c|c|c|c|c|c|c|c|c|c|c|c|}
\hline \multirow{2}{*}{ Species/Substances } & \multicolumn{2}{|c|}{ PPD-1 } & \multicolumn{2}{|c|}{ PPD-2 } & \multicolumn{2}{|c|}{ PPD-3 } & \multicolumn{2}{|c|}{ PPD-4 } & \multicolumn{2}{|c|}{ PPD-5 } & \multicolumn{2}{|c|}{ PPD-6 } \\
\hline & MIC $^{a}$ & $\mathbf{M M C}^{\mathbf{b}}$ & MIC & MMC & MIC & MMC & MIC & MMC & MIC & MMC & MIC & MMC \\
\hline Bacillus subtilis & $>1000$ & $>1000$ & $>1000$ & $>1000$ & $>1000$ & $>1000$ & $>1000$ & $>1000$ & $>1000$ & $>1000$ & $>1000$ & $>1000$ \\
\hline Bacillus subtilis ATCC 6633 & 1000 & $>1000$ & 1000 & $>1000$ & 1000 & 1000 & 1000 & $>1000$ & 1000 & $>1000$ & 1000 & $>1000$ \\
\hline Staphylococcus aureus ATCC 25923 & $>1000$ & $>1000$ & 1000 & $>1000$ & 1000 & $>1000$ & $>1000$ & $>1000$ & $>1000$ & $>1000$ & $>1000$ & $>1000$ \\
\hline Proteus mirabilis ATCC 12453 & 500 & 500 & $>1000$ & $>1000$ & $>1000$ & $>1000$ & $>1000$ & $>1000$ & $>1000$ & $>1000$ & 1000 & $>1000$ \\
\hline Pseudomonas aeruginosa ATCC 27853 & $>1000$ & $>1000$ & $>1000$ & $>1000$ & $>1000$ & $>1000$ & $>1000$ & $>1000$ & $>1000$ & $>1000$ & $>1000$ & $>1000$ \\
\hline Escherichia coli ATCC 25922 & 1000 & 1000 & $>1000$ & $>1000$ & $>1000$ & $>1000$ & 1000 & 1000 & $>1000$ & $>1000$ & $>1000$ & $>1000$ \\
\hline Escherichia coli & 1000 & 1000 & $>1000$ & $>1000$ & $>1000$ & $>1000$ & $>1000$ & $>1000$ & $>1000$ & $>1000$ & $>1000$ & $>1000$ \\
\hline Salmonella enterica & $>1000$ & $>1000$ & $>1000$ & $>1000$ & $>1000$ & $>1000$ & $>1000$ & $>1000$ & $>1000$ & $>1000$ & $>1000$ & $>1000$ \\
\hline
\end{tabular}

Table 2. continue

\begin{tabular}{|c|c|c|c|c|c|c|c|c|c|c|}
\hline \multirow{2}{*}{ Species/Substances } & \multicolumn{2}{|c|}{ PPD-7 } & \multicolumn{2}{|c|}{ PPD-8 } & \multicolumn{2}{|c|}{ PPD-9 } & \multicolumn{2}{|c|}{ PPD-10 } & \multicolumn{2}{|c|}{ Doxycycline } \\
\hline & MIC & MMC & MIC & MMC & MIC & MMC & MIC & MMC & MIC & МMC \\
\hline Bacillus subtilis & $>1000$ & $>1000$ & $>1000$ & $>1000$ & 250 & 500 & $>1000$ & $>1000$ & 0.112 & 1.953 \\
\hline Bacillus subtilis ATCC 6633 & 1000 & $>1000$ & 1000 & $>1000$ & 125 & 125 & 1000 & $>1000$ & 1.953 & 31.25 \\
\hline Staphylococcus aureus ATCC 25923 & 1000 & $>1000$ & $>1000$ & $>1000$ & 125 & 250 & 1000 & $>1000$ & 0.224 & 3.75 \\
\hline Proteus mirabilis ATCC 12453 & $>1000$ & $>1000$ & 1000 & $>1000$ & $>1000$ & $>1000$ & $>1000$ & $>1000$ & 15.625 & 62.5 \\
\hline Pseudomonas aeruginosa ATCC 27853 & $>1000$ & $>1000$ & $>1000$ & $>1000$ & 1000 & 1000 & $>1000$ & $>1000$ & 62.5 & 125 \\
\hline Escherichia coli & $>1000$ & $>1000$ & 1000 & 1000 & 1000 & 1000 & $>1000$ & $>1000$ & 15.625 & 31.25 \\
\hline Escherichia coli ATCC 25922 & $>1000$ & $>1000$ & 1000 & 1000 & 1000 & 1000 & $>1000$ & $>1000$ & 7.81 & 15.625 \\
\hline Salmonella enterica & $>1000$ & $>1000$ & $>1000$ & $>1000$ & $>1000$ & $>1000$ & $>1000$ & $>1000$ & 15.625 & 31.25 \\
\hline
\end{tabular}


Table 3. Antifungal activity of tested compounds.

\begin{tabular}{|c|c|c|c|c|c|c|c|c|c|c|c|c|}
\hline \multirow{2}{*}{ Species/Substances } & \multicolumn{2}{|c|}{ PPD-1 } & \multicolumn{2}{|c|}{ PPD-2 } & \multicolumn{2}{|c|}{ PPD-3 } & \multicolumn{2}{|c|}{ PPD-4 } & \multicolumn{2}{|c|}{ PPD-5 } & \multicolumn{2}{|c|}{ PPD-6 } \\
\hline & MIC $^{\mathbf{a}}$ & $\mathbf{M M C}^{\mathbf{b}}$ & MIC & MMC & MIC & MMC & MIC & MMC & MIC & MMC & MIC & MMC \\
\hline Rhodotorula mucilaginosa & 500 & $>1000$ & $>1000$ & $>1000$ & 500 & $>1000$ & 500 & $>1000$ & 500 & $>1000$ & 500 & $>1000$ \\
\hline Candida albicans ATCC 10231 & 1000 & 1000 & 250 & 1000 & 250 & $>1000$ & 1000 & $>1000$ & 1000 & $>1000$ & $>1000$ & $>1000$ \\
\hline Saccharomyces boulardii & 250 & 1000 & 125 & 1000 & 500 & $>1000$ & 500 & 1000 & 250 & 1000 & 500 & $>1000$ \\
\hline Penicillium italicum & 1000 & 1000 & 500 & 500 & $>1000$ & $>1000$ & $>1000$ & $>1000$ & $>1000$ & $>1000$ & 1000 & $>1000$ \\
\hline Penicillium chrysoge & 250 & 1000 & 125 & 1000 & 250 & 1000 & 250 & 1000 & 250 & 1000 & $>1000$ & $>1000$ \\
\hline edo ATTC 5 & 250 & 500 & 250 & $>1000$ & 1000 & 1000 & 1000 & 1000 & 250 & 1000 & 1000 & $>1000$ \\
\hline Trichodern & 500 & 1000 & & 1000 & 500 & 10 & 500 & 10 & 50 & 1000 & 500 & 1000 \\
\hline Aspergillus flavus A] & 1000 & 1000 & 00 & 1000 & 500 & $>1000$ & 1000 & $>1000$ & 1000 & $>1000$ & 500 & 1000 \\
\hline Aspergillus fumigatus & 500 & 1000 & 500 & 1000 & 250 & 1000 & 250 & 1000 & 500 & 1000 & 500 & 1000 \\
\hline Aspergillus niger ATCC 16404 & 1000 & 1000 & 500 & $>1000$ & 500 & 1000 & 500 & $>1000$ & 500 & 1000 & 1000 & $>1000$ \\
\hline
\end{tabular}

${ }^{a}$ Minimal inhibitory concentration (MIC) values are given as $\mu \mathrm{g} / \mathrm{mL}$;

${ }^{\mathrm{b}}$ Minimum microbicidal concentration (MMC) values are given as $\mu \mathrm{g} / \mathrm{mL}$;

Table 3. continue

\begin{tabular}{|c|c|c|c|c|c|c|c|c|c|c|}
\hline \multirow{2}{*}{ Species/Substances } & \multicolumn{2}{|c|}{ PPD-7 } & \multicolumn{2}{|c|}{ PPD-8 } & \multicolumn{2}{|c|}{ PPD-9 } & \multicolumn{2}{|c|}{ PPD-10 } & \multicolumn{2}{|c|}{ Fluconazole } \\
\hline & MIC & MMC & MIC & MMC & MIC & MMC & MIC & MMC & MIC & MMC \\
\hline Rhodc & $>1000$ & $>1000$ & 500 & $>1000$ & 500 & 1000 & $>1000$ & $>1000$ & 31.25 & 500 \\
\hline Candida albic & 500 & 1000 & 250 & $>1000$ & 1000 & $>1000$ & $>1000$ & $>1000$ & 31.25 & 62.5 \\
\hline Saccharomyces boulardii & 250 & $>1000$ & 250 & $>1000$ & 500 & 1000 & 500 & & 7.81 & 31.25 \\
\hline Penicillium italicum & 1000 & 1000 & 1000 & & 1000 & & 000 & & 250 & \\
\hline Penic & 50 & 1000 & 1000 & $>1000$ & 500 & 1000 & 250 & 1000 & 1000 & 1000 \\
\hline Mucorn & 500 & 1000 & 1000 & 1000 & 1000 & 1000 & 1000 & $>1000$ & 250 & 250 \\
\hline Trichoderma viridae ATCC 13233 & 1000 & 1000 & 500 & 1000 & 500 & 1000 & 1000 & 1000 & 500 & 1000 \\
\hline Aspergillus flavus ATCC 9170 & 1000 & $>1000$ & 1000 & 1000 & 1000 & $>1000$ & 1000 & $>1000$ & 500 & 500 \\
\hline Aspergillus fumigatus ATTC 204305 & 500 & 1000 & 500 & 1000 & 1000 & 1000 & 1000 & 1000 & 1000 & 1000 \\
\hline Aspergillus niger ATCC 16404 & 500 & $>1000$ & 1000 & 1000 & 1000 & $>1000$ & 500 & $>1000$ & 1000 & 1000 \\
\hline
\end{tabular}




\section{Antimicrobial activity}

The results of in vitro testing of antibacterial and antifungal activities of the synthetized substances and positive controls (doxycycline and fluconazole) are shown in Tabs. 2 and 3. The tested substances did not affect the growth of clinical isolates and standard strains of bacteria, or their activities were very low (MICs and MMCs ranged from 1000 to $>1000$ $\mu \mathrm{g} / \mathrm{mL}$ ). P. mirabilis ATCC 12453 was slightly more sensitive to the compound PPD-1 with unsubstituted phenyl moiety (MIC and MMC was at $500 \mu \mathrm{g} / \mathrm{mL}$ ). The exception are grampositive bacteria (Bacillus subtilis, Bacillus subtilis ATCC 6633 and Staphylococcus aureus ATCC 25923) that showed moderate susceptibility to compound PPD-9 with syringic moiety (MICs values were between 125-250 $\mu \mathrm{g} / \mathrm{mL}$ and MMCs values were between 125-500 $\mu \mathrm{g} / \mathrm{mL}$ ). The previous research of antimicrobial activity of different PPDs provides diverse conclusions. Compared to the activity of the standard drug ampicillin, some of them act on bacteria almost equipotent or more potent (SANGANi et al., 2016). Many PPDs are found to be more active against $B$. subtilis than to the rest of the tested species: Streptococcus pneumonia, Clostridium tetani, Salmonella typhi, Vibrio cholera, Escherichia coli (SHAH et al., 2012).

The fungi showed higher sensitivity to the tested substances. MICs values were mostly in the range from 125 to $1000 \mu \mathrm{g} / \mathrm{mL}$, and MMCs values were in range from 500 to $>1000 \mu \mathrm{g} / \mathrm{mL}$. Saccharomyces boulardii and Penicillium chrysogenum were the most sensitive to compound PPD-2 with toluic moiety, with MICs value at $125 \mu \mathrm{g} / \mathrm{mL}$. Tested substances expressed slightly better antifungal activity on Aspergillus fumigatus ATTC 204305 than on positive control (fluconazole), while on Trichoderma viridae ATCC 13233 activity is similar to the activity of fluconazole.

Antifungal activity of the PPDs shows that many of them are found to be potent against $C$. albicans. (SHAH et al., 2012) Against this fungal pathogen, some PPDs possess excellent activity (MIC at $100 \mu \mathrm{g} / \mathrm{mL}$ ), while other moderate (MIC at $250 \mu \mathrm{g} / \mathrm{mL}$ ), but still higher than the standard drug griseofulvin (MIC at $500 \mu \mathrm{g} / \mathrm{mL}$ ). It is important to emphasize that, unlike our research, previously reported compounds were found to be inactive against $A$. fumigates (SANGANI et al., 2016). Our study points out compounds PPD-3 and PPD-4 with $p-\mathrm{Cl}$ and $p-\mathrm{F}$ substituents on phenyl moiety as compounds with pronounced activity towards this pathogen (MIC at $250 \mu \mathrm{g} / \mathrm{mL}$ ), much higher than activity of control probe fluconazole.

\section{CONCLUSION}

Pyrazolyl-phthalazine-dione derivatives (PPDs) were tested for their in vitro antiLOX and antimicrobial activity. Generally, all examined compounds exhibit good to excellent anti-LOX activity. Compounds PPD-2 and PPD-10 provided the highest LOX inhibition with $\mathrm{IC}_{50}$ values at about $24 \mu \mathrm{M}$, as well as PPD-8 and PPD-9 with $\mathrm{IC}_{50}$ values at about $28 \mu \mathrm{M}$. Other compounds exhibit slightly lower activity. To get the insight in structure-based activity relationship and bioactive conformations of PPDs during the LOX-Ib inhibition, molecular modeling study was done. On the basis of docking results it can be concluded that activity of PPDs is significantly influenced by the orthogonal spatial arrangement between the $1 H$-pyrazolo[1,2-b]phthalazine-5,10-dione basic core and with substituents on the phenyl group attached to $\mathrm{C} 11$. The presence of substituents bearing both, hydrogen bond accepting (HBA) and hydrophobic features (Hy), allows the formation of HBA-Hy features which are mandatory structural motif of the LOX-Ib active site interior. The results of antimicrobial activity revealed that investigated compounds exhibited low antibacterial activity, and better antifungal activity. Compounds containing $\mathrm{Cl}$ and $\mathrm{F}$ as substituents, PPD-3 and PPD-4, 
expressed pronounced activity towards A. fumigates, much higher than positive control fluconazole, as well as compounds of this type. Based on the obtained results one can conclude that PPDs can be candidates for the further examination of their in vitro and in vivo antiinflammatory activity.

\section{Acknowledgments}

This work was supported by the Serbian Ministry of Education, Science and Technological Development (Agreement Nos. 451-03-9/2021-14/200122 and 451-03-9/202114/200378).

\section{References:}

[1] Abd El RaziK, H.A., Badr, M.H., Atta, A.H., Mouneir, S.M., Abu-SERie, M.M. (2017): Benzodioxole-Pyrazole Hybrids as Anti-Inflammatory and Analgesic Agents with COX-1,2/5-LOX Inhibition and Antioxidant Potential. Archiv Der Pharmazie 350 (5): 1700026. doi: 10.1002/ardp.201700026

[2] Abdelall, E.K.A., Lamie, P.F., Ali, W.A.M. (2016): Cyclooxygenase-2 and 15lipoxygenase inhibition, synthesis, anti-inflammatory activity and ulcer liability of new celecoxib analogues: Determination of region-specific pyrazole ring formation by NOESY. Bioorganic \& Medicinal Chemistry Letters 26 (12): 2893-2899. doi: 10.1016/j.bmcl.2016.04.046

[3] ANDREWS, J.M., (2005): BSAC standardized disc susceptibility testing method (version 4). Journal of Antimicrobial Chemotherapy 56: 60-76 doi: 10.1093/jac/dki124

[4] AsIF, M. (2015): A brief review on pharmacological effect of some phthalazine derivatives on cardiovascular and kidney functions. CIBTech Journal of Pharmaceutical Sciences 4 (1): 17-26.

[5] Bergstrom, F.W. (1944): Heterocyclic nitrogen compounds Part II A. Hexacyclic Compounds: Pyridine, Quinoline, and Isoquinoline. Chemical Reviews 35 (2): 77-277. doi: 10.1021/cr601119001

[6] Curioni, C., André, C. (2006): Rimonabant for overweight or obesity. Cochrane Database of Systematic Reviews 4. doi: 10.1002/14651858.CD006162.pub2

[7] Case, D.A., Darden, T.A., Cheatham III, T.E., Simmerling, C.L., Wang, J., Duke, R.E., Luo, R., Walker, R.C., Zhang, W., Merz, K.M., Roberts, B., HaYik, S., Roitberg, A., Seabra, G., Swails, J., Götz, A.W., Kolossváry, I., Wong, K.F., PAesani, F., VANiceK, J., Wolf, R.M., LiU, J., Wu, X., Brozell, S.R., Steinbrecher, T., Gohlke, H., Cai, Q., Ye, X., Wang, J., Hsieh, M.J., Cui, G., Roe, D.R., Mathews, D.H., Seetin, M.G., SAlomon-Ferrer, R., SAgui, C., Babin, V., LuchKo, T., Gusarov, S., Kovalenko, A., Kollman, P.A. (2012): AMBER 12, University of California, San Francisco.

[8] El-SakKa, S.S., Soliman, A.H., Imam, A.M. (2009): Synthesis, antimicrobial activity and Electron Impact of Mass Spectra of Phthalazine-1,4-dione Derivatives. Afinidad: Revista de Quimica Teorica y Aplicada 66 (540): 167-172.

[9] Genin, M.J., Biles, C., Keiser, B.J., Poppe, S.M., Swaney, S.M., Tarpley, W.G., YagI, Y., Romero, D.L. (2000): Novel 1,5-Diphenylpyrazole Nonnucleoside HIV-1 
Reverse Transcriptase Inhibitors with Enhanced Activity versus the Delavirdine-Resistant P236L Mutant: Lead Identification and SAR of 3- and 4-Substituted Derivatives. Journal of Medicinal Chemistry 43 (5): 1034-1040. doi: 10.1021/jm990383f

[10] Grasso, S., De Sarro, G., De Sarro, A., Micale, N., Zappala, M., Puja, G., Baraldi, M., DE Micheli, C. (2000): Synthesis and Anticonvulsant Activity of Novel and Potent 6,7-Methylenedioxyphthalazin-1(2H)-ones. Journal of Medicinal Chemistry 43 (15): 2851-2859. doi: 10.1021/jm001002x

[11] Groves, B.M., Rubin, L.J., Frosolono, M.F., Cato, A.E., Reeves, J. T. (1985): A comparison of the acute hemodynamic effects of prostacyclin and hydralazine in primary pulmonary hypertension. American Heart Journal 110 (6): 1200-1204.

doi:10.1016/0002-8703(85)90013-4

[12] Hu, C., MA, S. (2018): Recent development of lipoxygenase inhibitors as antiinflammatory agents. Medicinal Chemistry Communications 9 (2): 212-225.

doi: 10.1039/C7MD00390K

[13] Jalili-Baleh, L., Nadri, H., Moradi, A., Bukhari, S.N.A., Shakibaie, M., Jafari, M., Golshani, M., Homayouni Moghadam, F., Firoozpour, L., Asadipour, A., EmAmi, S., KHOOBI, M., Foroumadi, A. (2017): New racemic annulated pyrazolo[1,2b]phthalazines as tacrine-like AChE inhibitors with potential use in Alzheimer's disease. European Journal of Medicinal Chemistry 139: 280-289.

doi: 10.1016/j.ejmech.2017.07.072

[14] Kim, J.S., Rhee, H.-K., PARK, H.J., Lee, S.K., LeE, C.-O., PARK ChOO, H.-Y. (2008): Synthesis of 1-/2-substituted-[1,2,3]triazolo[4,5-g]phthalazine-4,9-diones and evaluation of their cytotoxicity and topoisomerase II inhibition. Bioorganic \& Medicinal Chemistry 16 (8): 4545-4550. doi: 10.1016/j.bmc.2008.02.049

[15] LichtenthaleR, F.W. (2002): Unsaturated O- and N- Heterocycles from Carbohydrate Feedstocks. Accounts of Chemical Research 35 (9): 728-737. doi: 10.1021/ar010071i

[16] Lv, P.-C., Sun, J., LuO, Y., YAnG, Y., Zhu, H.-L. (2010): Design, synthesis, and structure-activity relationships of pyrazole derivatives as potential FabH inhibitors. Bioorganic \& Medicinal Chemistry Letters 20 (15): 4657-4660.

doi: 10.1016/j.bmcl.2010.05.105

[17] Marvin BeAns 15.4.27.0, 2015, Chem Axon (http://www.chemaxon.com). Accessed January 2015.

[18] Mladenović, M., Patsilinakos, A., Pirolli, A., Sabatino, M., Ragno, R. (2017): Understanding the Molecular Determinant of Reversible Human Monoamine Oxidase B Inhibitors Containing 2H-Chromen-2-One Core: Structure-Based and Ligand-Based Derived Three-Dimensional Quantitative Structure-Activity Relationships Predictive Journal of Chemical Information and Modeling 57: 787-814.

doi: 10.1021/acs.jcim.6b00608

[19] Morris, G.M., Huey, R., Lindstrom, W., SAnner, M.F., Belew, R.K., Goodsell, D.S., \& Olson, A.J. (2009): AutoDock4 and AutoDockTools4: Automated docking with selective receptor flexibility. Journal of Computational Chemistry 30 (16): 27852791. doi: $10.1002 /$ jcc. 21256

[20] MüLLER, K. (1994): 5-Lipoxygenase and 12-lipoxygenase: attractive targets for the development of novel antipsoriatic drugs. Archiv Der Pharmazie 327 (1): 3-19. http://www.ncbi.nlm.nih.gov/pubmed/8117187 
[21] Mylari, B.L., Larson, E.R., Beyer, T.A., Zembrowski, W.J., Aldinger, C.E., DeE, M.F., Siegel, T.W., Singleton, D.H. (1991): Novel, Potent Aldose Reductase Inhibitors: 3,4-Dihydro-4-oxo-3-[[5-(trifluoromethyl)-2-benzothiazolyl]methyl]-1-phthalazine- acetic Acid (Zopolrestat) and Congeners. Journal of Medicinal Chemistry 34 (1): 108-122. doi: 10.1021/jm00105a018

[22] NABid, M.R., Jamal, S., Rezaei, T., GHahremanzadeh, R., BAZgiR, A. (2010): Ultrasonics Sonochemistry Ultrasound-assisted one-pot, three-component synthesis of $1 \mathrm{H}-$ pyrazolo[1,2-b]phthalazine-5,10-diones Ultrasonics Sonochemistry 17 (1): 159-161. doi: 10.1016/j.ultsonch.2009.06.012

[23] Nakamura, T., Sato, M., Kakinuma, H., Miyata, N., Taniguchi, K., Bando, K., KodA, A., KAMEO, K. (2003): Pyrazole and Isoxazole Derivatives as New, Potent, and Selective 20-Hydroxy-5,8,11,14-eicosatetraenoic Acid Synthase Inhibitors. Journal of Medicinal Chemistry 46 (25): 5416-5427. doi: 10.1021/jm020557k

[24] NCCLS. (1998). (National Commitee for Clinical Laboratory Standards) Reference method for broth dilution antifungal susceptibility testing of conidium-forming filamentous fungi: Proposed Standard M38-P. NCCLS, Wayne, PA, USA.

[25] Nomoto, Y., Obase, H., TAKal, H., Teranishi, M., NaKamura, J., Kubo, K. (1990): Studies on Cardiotonic Agents. II. Synthesis of Novel Phthalazine and 1,2,3-Benzotriazine Derivatives. Chemical and Pharmaceutical Bulletin 38 (8): 2179-2183.

[26] Petrović, Z.D., Đorović, J., Simijonović, D., Trifunović, S., Petrović, V.P. (2018): In vitro study of iron coordination properties, anti-inflammatory potential, and cytotoxic effects of $\mathrm{N}$-salicylidene and N-vanillidene anil Schiff bases. Chemical Papers 72 (9): 2171-2180. doi: 10.1007/s11696-018-0419-5

[27] Petrović, Z.D., Hadjipavlou-Litina, D., Pontiki, E., Simijonović, D., Petrović, V.P. (2009): Diethanolamine Pd(II) complexes in bioorganic modeling as model systems of metallopeptidases and soybean lipoxygenase inhibitors. Bioorganic Chemistry 37 (5): 162-166. doi: 10.1016/j.bioorg.2009.07.003

[28] Pettersen, E.F., Goddard, T.D., Huang, C.C., Couch, G.S., Greenblatt, D.M., MENG, E.C., FERRIN, T.E. (2004): UCSF Chimera-A visualization system for exploratory research and analysis. Journal of Computational Chemistry 25 (13): 1605-1612. doi: $10.1002 /$ jcc. 20084

[29] Phatak, P., Sumner, I., IYengar, S.S. (2012): Gauging the Flexibility of the Active Site in Soybean Lipoxygenase-1 (SLO-1) through an Atom-Centered Density Matrix Propagation (ADMP) Treatment That Facilitates the Sampling of Rare Events. The Journal of Physical Chemistry B 116 (34): 10145-10164. doi: 10.1021/jp3015047

[30] Pontiki, E., HadjiPavlou-Litina, D. (2007): Synthesis and pharmacochemical evaluation of novel aryl-acetic acid inhibitors of lipoxygenase, antioxidants, and anti-inflammatory agents. Bioorganic \& Medicinal Chemistry 15 (17): 5819-5827.

doi: 10.1016/j.bmc.2007.06.001

[31] Pontiki, E., Hadjipavlou-Litina, D. (2018): Multi-Target Cinnamic Acids for Oxidative Stress and Inflammation: Design, Synthesis, Biological Evaluation and Modeling Studies. Molecules 24 (1): 12. doi: 10.3390/molecules24010012

[32] Ragno, R., Frasca, S., Manetti, F., Brizzi, A., Massa S. (2005): HIV-Reverse Transcriptase Inhibition: Inclusion of Ligand-Induced Fit by Cross-Docking Studies. Journal of Medicinal Chemistry 48: 200-212. doi: 10.1021/jm0493921 
[33] RyU, C., PARK, R., MA, M., NhO, J. (2007): Synthesis and antifungal activity of 6arylamino-phthalazine-5,8-diones and 6,7-bis(arylthio)-phthalazine-5,8-diones. Bioorganic \& Medicinal Chemistry Letters 17 (9): 2577-2580.

doi: 10.1016/j.bmcl.2007.02.003

[34] Sangani, C.B., Makwana, J.A., Duan, Y.-T., Thumar, N.J., ZhaO, M.-Y., Patel, Y.S., ZHU, H.-L. (2016): Synthesis of 1H-pyrazolo[1,2-b]phthalazine-5,10-dione derivatives: assessment of their antimicrobial, antituberculosis and antioxidant activity. Research on Chemical Intermediates 42 (3): 2101-2117. doi: 10.1007/s11164-0152138-7

[35] SARKer, S.D., NAhar, L., Kumarasamy, Y. (2007): Microtitre plate-based antibacterial assay incorporating resazurin as an indicator of cell growth, and its application in the in vitro antibacterial screening of phytochemicals. Methods 42 (4): 321-324. doi: 10.1016/j.ymeth.2007.01.006

[36] Segal, H.L., Rumbold, J.C., Friedman, B.L., Finigan, M.M. (1959): Detection of Achlorhydria by Tubeless Gastric Analysis with Betazole Hydrochloride as the Gastric Stimulant. New England Journal of Medicine 261 (11): 544-546. doi: 10.1056/NEJM195909102611105

[37] Shah, N.M., Patel, M.P., Patel, R.G. (2012): An Efficient and Facile Synthesis of 1H-Pyrazolo[1,2-b] phthalazine-5,10-dione Derivatives of Biological Interest. Journal of Heterocyclic Chem 49 (6): 1310-1316. doi: 10.1002/jhet.918

[38] Simijonović, D., Petrović, Z. D., Milovanović, V. M., Petrović, V. P., BogdanoVIĆ, G. A. (2018): A new efficient domino approach for the synthesis of pyrazolylphthalazine-diones. Antiradical activity of novel phenolic products. RSC Advances 8 (30): 16663-16673. doi: 10.1039/C8RA02702A

[39] Simijonović, D., Vlachou, E.-E., Petrović, Z.D., HadjiPAVlou-Litina, D.J., Litinas, K.E., Stanković, N., Minović, N., Mladenović, M.P. (2018): Dicoumarol derivatives: Green synthesis and molecular modelling studies of their anti-LOX activity. Bioorganic Chemistry 80: 741-752. doi: 10.1016/j.bioorg.2018.07.021

[40] Skrzypczak-Jankun, E., Bross, R.A., Carroll, R.T., Dunham, W.R., Funk, M.O. (2001): Three-Dimensional Structure of a Purple Lipoxygenase. Journal of the American Chemical Society 123 (44): 10814-10820. doi: 10.1021/ja011759t

[41] Srivastava, P., Vyas, V.K., Variya, B., Patel, P., Qureshi, G., Ghate, M. (2016): Synthesis, anti-inflammatory, analgesic, 5-lipoxygenase (5-LOX) inhibition activities, and molecular docking study of 7-substituted coumarin derivatives. Bioorganic Chemistry 67: 130-138. doi: 10.1016/j.bioorg.2016.06.004

[42] Torres, R., Mascayano, C., NúÑez, C., Modak, B., Faini, F. (2013): Coumarins of haplopappus multifolius and derivative as inhibitors of lox: evaluation in-vitro and docking studies. Journal of the Chilean Chemical Society 58 (4): 2027-2030. doi: 10.4067/S0717-97072013000400027

[43] Uslaner, J.M., Parmentier-Batteur, S., Flick, R.B., Surles, N.O., Lam, J.S.H., MCNaughton, C.H., JaCOBSOn, M.A., Hutson, P.H. (2009): Dose-dependent effect of CDPPB, the mGluR5 positive allosteric modulator, on recognition memory is associated with GluR1 and CREB phosphorylation in the prefrontal cortex and hippocampus. Neuropharmacology 57 (5-6): 531-538.

doi: 10.1016/j.neuropharm.2009.07.022 
[44] Vinayagam, J., Gajbhiye, R.L., Mandal, L., Arumugam, M., Achari, A., JaiSANKAR, P. (2017): Substituted furans as potent lipoxygenase inhibitors: Synthesis, in vitro and molecular docking studies. Bioorganic Chemistry 71: 97-101. doi: 10.1016/j.bioorg.2017.01.016

[45] Watanabe, N., Kabasawa, Y., Takase, Y., Matsukura, M., \& MiYaZaKi, K. (1998): 4-Benzylamino-1-chloro-6-substituted Phthalazines: Synthesis and Inhibitory Activity toward Phosphodiesterase 5. Journal of Medicinal Chemistry 41 (18): 3367-3372. doi: $10.1021 / \mathrm{jm} 970815 \mathrm{r}$

[46] Wei, F., Zhao, B., Huang, B., Zhang, L., Sun, C., Dong, W., Shin, D., Miao, J. (2006): Design, synthesis, and preliminary biological evaluation. Bioorganic \& Medicinal Chemistry Letters 16: 6342-6347. doi: 10.1016/j.bmcl.2006.09.008

[47] Wisastra, R., DEKKER, F. (2014): Inflammation, Cancer and Oxidative Lipoxygenase Activity are Intimately Linked. Cancers 6 (3): 1500-1521. doi: 10.3390/cancers6031500

[48] Xia, Y., Dong, Z., Zhao, B., Ge, X., Meng, N., Shin, D.-S., Miao, J.-Y. (2007): Synthesis and structure-activity relationships of novel 1-arylmethyl-3-aryl-1Hpyrazole-5-carbohydrazide derivatives as potential agents against A549 lung cancer cells. Bioorganic \& Medicinal Chemistry 15 (22): 6893-6899.

doi: 10.1016/j.bmc.2007.08.021 